\title{
Flood-ebb disparity of tidally induced recirculation Eddies in a semi-enclosed basin: Nan Wan Bay
}

\author{
Hung-Jen Lee ${ }^{\mathrm{a}, *}$, Shenn-Yu Chao ${ }^{\mathrm{b}}$, Kuang-Lung Fan ${ }^{\mathrm{a}}$ \\ ${ }^{a}$ Institute of Oceanography, National Taiwan University, Taipei, Taiwan, ROC \\ ${ }^{\mathrm{b}}$ Horn Point Laboratory, University of Maryland, Center for Environmental Science, \\ Cambridge, MD 21613-0775, USA
}

Received 7 August 1997; received in revised form 4 September 1998; accepted 4 November 1998

\begin{abstract}
Nan Wan Bay is a semi-enclosed basin forming the southern tip of Taiwan. Around spring tides, a recirculating cyclonic eddy occupying a good portion of the basin develops daily during the ebb current. The eddy induces sudden temperature drops inside the Bay lasting for a few hours each. An anticyclonic recirculation eddy, if any, is much reduced in size and confined to the eastern side of the basin during the flood current. Mechanisms leading to the flood-ebb disparity of recirculation eddies are investigated below using a three-dimensional numerical tidal model. By systematically adding or removing topographic features in and around Nan Wan, the process of elimination points to two topographic features that are responsible for the flood-ebb disparity. One is a bottom ridge around the eastern cape of the Bay; the other is an elongated seamount along the mouth of the semi-enclosed basin. These topographic features deflect tidal currents in the anticyclonic sense. Bayward and seaward deflections of tidal currents weaken and strengthen recirculating eddies, respectively, producing the flood-ebb disparity. The two topographic features enhance the cyclonic eddy during ebb, especially when the prevailing tidal current off the Bay is strong. For a typical embayment with tidal currents parallel to the bay mouth, the cyclonic eddy is expected to dominate over the anticyclone if there is a prominent seamount blocking the middle reaches of the mouth region. (C) 1999 Elsevier Science Ltd. All rights reserved.
\end{abstract}

Keywords: Eddy; Sudden temperature drops; Tidal current; Seamount

* Corresponding author. 


\section{Introduction}

The southernmost embayment of Taiwan, locally known as Nan Wan (Fig. 1), is a semi-enclosed basin bounded zonally by two capes. The eastern cape, locally known as O-Luan-Bi (hereafter OLB), projects into the ocean farther south than does the western cape, locally known as Mou-Bi-Tou (MBT). The semi-enclosed basin borders the Pacific Ocean to its east and the Taiwan Strait to its west. To its south is the Luzon Strait that links the South China Sea and the Pacific Ocean. The distance between two capes is about $14 \mathrm{~km}$. There is practically no continental shelf in the relatively deeper, western half of the basin. The eastern half of the basin is characterized by a broad (about $4 \mathrm{~km}$ wide) continental shelf with isobaths running more or less parallel to the coastline. The southward excursion of the eastern continental shelf forms an extended bottom ridge to the south of OLB. To the south of Nan Wan, passage to the open ocean is partially blocked by a zonally elongated seamount, reaching as high as $50 \mathrm{~m}$ beneath the mean sea level. Sandwiched between the seamount and the land masses of Nan Wan is an arc-shaped deep channel.

Circulation in and about Nan Wan is dominated by tides. Diurnal and semi-diurnal tides are about equal in amplitude (Liang et al., 1978); both are modulated by a

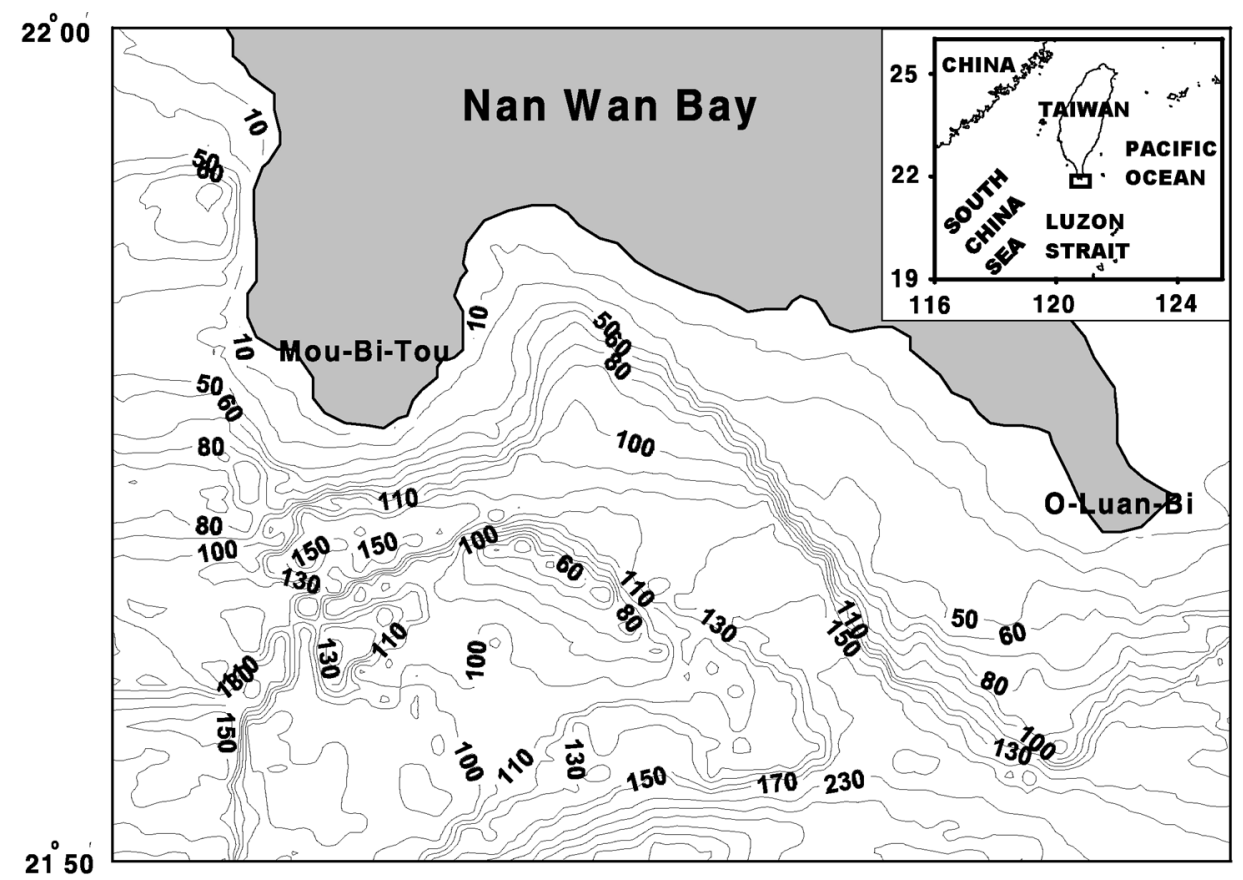

$120^{\circ} 41$

$120^{\circ} 53$

Fig. 1. Map and bottom topography of Nan Wan Bay, with depth contours in meters. Top right inset is the large-scale setting. 

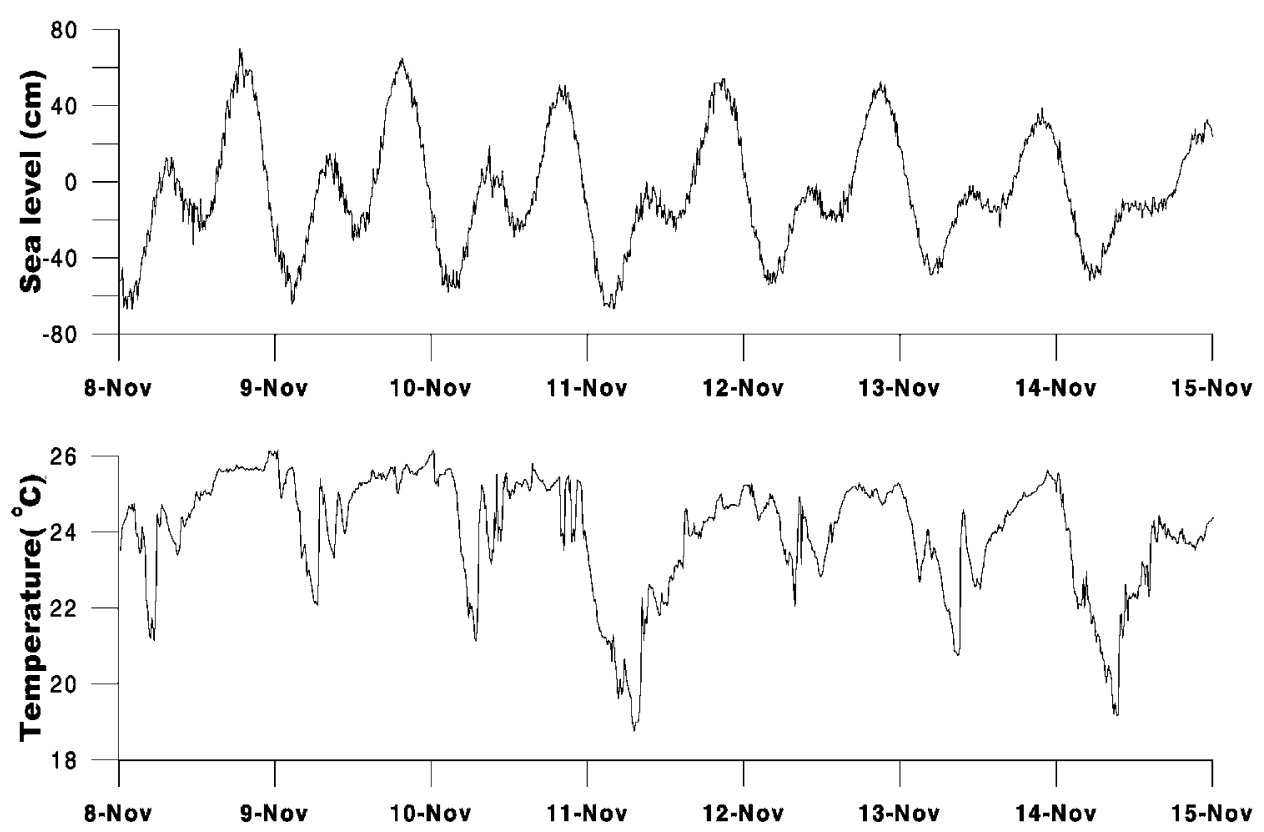

Fig. 2. Typical sea level (top) and temperature (bottom) time series around a spring period in Nan Wan, November 1995. Sea level was measured at station S5 and temperatures were measured at Station V at $45 \mathrm{~m}$ below the mean sea level. See Fig. 5 for locations of stations.

pronounced spring-neap cycle. Tidal range reaches $1.6 \mathrm{~m}$ during springs, but is reduced to about $0.6 \mathrm{~m}$ during neaps. During springs, the two tides of the day have highly unequal ranges (Fig. 2). The ebb tide is characterized by a rapid drop from higher high water to lower low water. The flood tide is protracted, beginning from lower low water to lower high water and, after a long stand or a small drop, from higher low water to higher high water. The lower high water and higher low water are often comparable during spring tides, creating the long stand in between.

Southward of Nan Wan, the prevailing tidal currents are essentially westward during flood and eastward during ebb (Li, 1987). Tidal streams are rather swift in and around Nan Wan. Speeds of tidal currents range up to $1.7 \mathrm{~m} / \mathrm{s}$ near OLB and MBT (Liang et al., 1978; Lee et al., 1997), decreasing by an order of magnitude in the shallow inner reaches of the embayment. Over the continental shelf on the east side of the Bay, tidal currents regularly reverse following rises and falls of sea level. In the west half of the basin, tidally induced circulation is more complex and often shows intra-tidal fluctuations, especially during spring tides.

Tidally induced upwelling often causes sudden temperature drops at diurnal frequencies in Nan Wan. The upwelling event occurs daily and preferably during spring tides (Lee et al., 1997). The cold water intrusion normally begins as the tide is approaching lower low water and peaks before lower high water, lasting for $6-8 \mathrm{~h}$ each (Fig. 2). In general, the subsequent temperature rise is more gradual than the sudden temperature drop. There may be as many as 3 or 4 cold events around a 


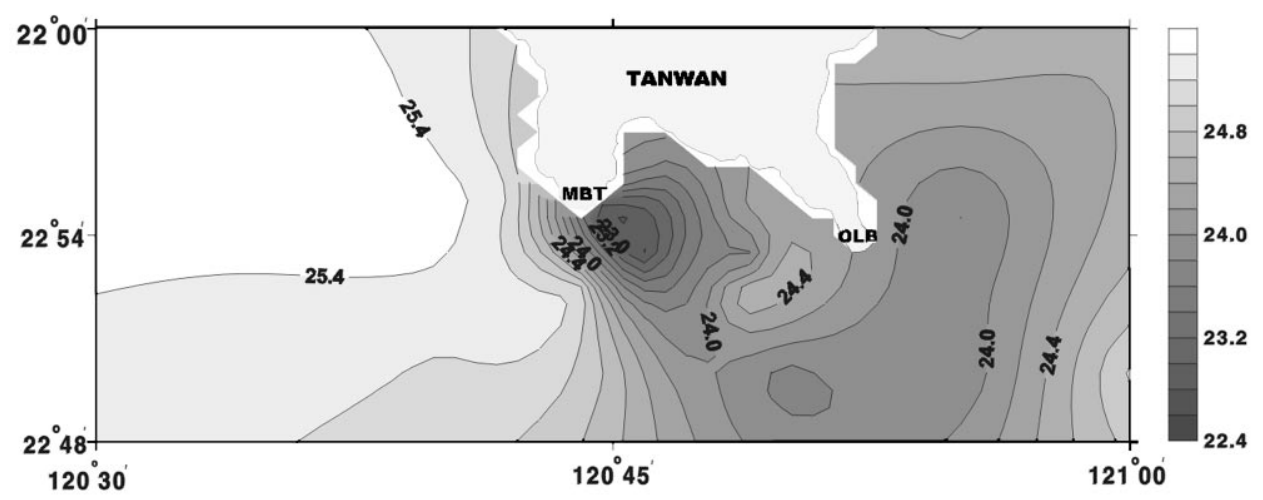

Fig. 3. Temperature field (in ${ }^{\circ} \mathrm{C}$ ) at $30 \mathrm{~m}$ depth around Nan Wan Bay on 27 March 1991.

typical spring period. Two consecutive events are $24 \mathrm{~h}$ and $50 \mathrm{~min}$ apart, in keeping with the period of diurnal tides. The cold event occurs regularly in all seasons. Possible modulations by northwesterly monsoon wind in winter and southeasterly wind in summer are apparently weak.

Tidally induced sudden temperature drops of the order of $2-3^{\circ} \mathrm{C}$ often occur over submarine canyons around the island of Taiwan (Wang and Chern, 1995). The amplitude of drops is undoubtedly much greater in Nan Wan, often exceeding $10^{\circ} \mathrm{C}$. In one widely publicized example on 24 November 1988, the cold event decreased the sea surface temperature to about $14^{\circ} \mathrm{C}$, resulting in mass kill of fishes. Conceivably, the intermittent cooling reduces the mean water temperature in and around Nan Wan. Ship surveys consistently indicate Nan Wan and its vicinity as a year-round source of cold anomalies. Fig. 3, based on the shipboard survey from $R / V$ Ocean Researcher I on 27 March 1991, shows the temperature field at $30 \mathrm{~m}$ depth. The cold anomaly up to $1^{\circ} \mathrm{C}$ or so seems centered about the arc-shaped deep channel. Ship surveys in other seasons and other years show a similar pattern with minor variations (Chen et al., 1994).

In October-December 1995, twelve temperature sensors, four current meters and six tide gauges were strategically deployed around Nan Wan to better identify the cold water intrusion process. Major findings were summarized in Lee et al. (1997); details will not be repeated below. It suffices to say that the intrusion begins at depths over the arc-shaped channel. The cold water at depths intrudes onto the embayment while ascending, spreading laterally thereafter (Fig. 4a). The process begins as the tide is

Fig. 4. (a) Inferred phase propagation at diurnal frequencies among temperature stations from the field experiment in October-December 1995. Time lags are given in hours. Stations S1-S6 and A were in shallow waters and temperature sensors were placed at depths less than $22 \mathrm{~m}$ from the mean sea surface. Temperature sensor at station S0 is $94 \mathrm{~m}$ below mean sea level. Temperature sensor at station $\mathrm{V}$ is in the arc-shaped channel and placed at $45 \mathrm{~m}$ depth below mean sea level. (b) Inferred pathways of upwelled cold waters from the arc-shaped channel at the end of ebb current during spring tidal period. The cyclonic arm of cold water intrusion attenuates with distance away from the upwelling center. 
(a)

\section{Nan Wan Bay}

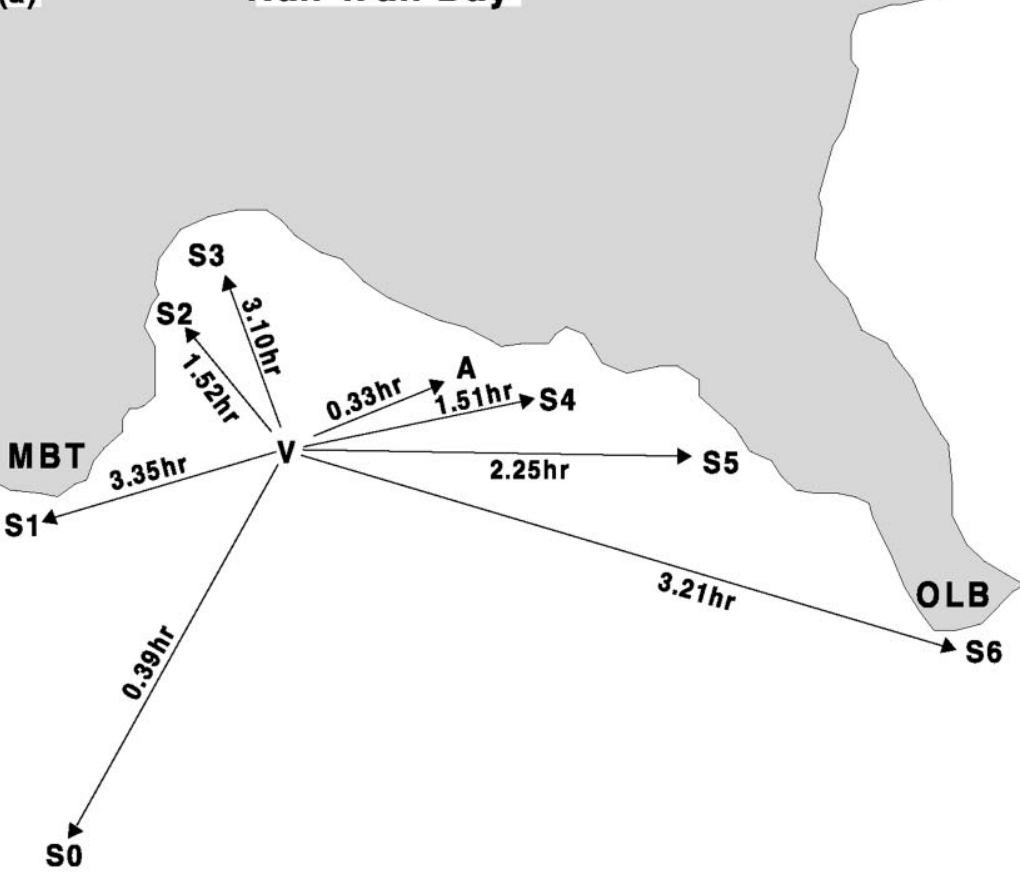

(b)

\section{Nan Wan Bay}

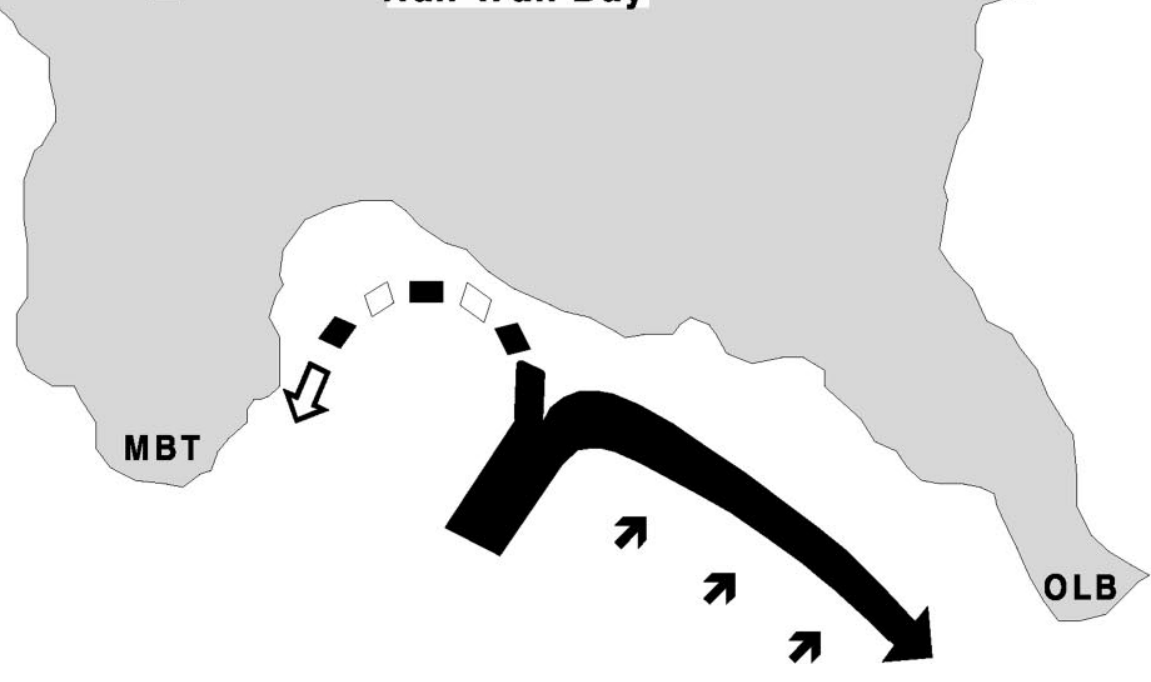


approaching the lower low water. The shoreward intruding current bifurcates in the inner Bay, forming a meander crest of the ebb current on the east half and a recirculating cyclonic eddy on the west half of the Bay (Fig. 4b). Temperature drops in conjunction with the formation of cyclonic eddy. The cyclonic eddy persists for several hours as the tide is turning from ebb to flood and disappears thereafter. The data also reveal that a counter-rotating anticyclonic recirculation eddy during flood is mostly absent, at least in the western half of the basin. The experiment confirms the long-suspected existence of a recirculation cyclone as tidal current is ebbing during spring tides (Su et al., 1980; Liang et al., 1978).

Since 1995, a three-dimensional tidal model for Nan Wan has been developed by the authors to examine the cold water intrusion process. After a modest amount of process-oriented modeling efforts, it became clear that the flood-ebb disparity in the development of recirculation eddies is a persistent dynamical feature for the tides in Nan Wan. Its persistence and the lack of existing literature to explain it motivated us to investigate this subject further.

If the earth's rotation is removed, and the coastline configuration and bottom topography are symmetric with respect to the center axis of a small embayment, then the flood-induced anticyclone and the ebb-induced cyclone should be comparable. Nan Wan presents sizeable departures from this symmetric limit. Leaving the effect of the Coriolis deflection aside, the continental shelf topography, coastline orientation, seamount and unequal protruding lengths of two capes all violate symmetry with respect to the center axis of the Bay. All of them are potentially responsible for the flood-ebb disparity in eddy formation. Our process of elimination begins from a simulation with realistic coastline and bottom topography. Further, only monochromatic tides will be considered to simplify the analysis. By systematically removing topographic features from the basin geometry, major mechanisms leading to the predominance of cyclonic recirculation eddies are identified in the process.

\section{Model formulation}

A three-dimensional tidal model is developed to facilitate the analysis. The model is formulated under hydrostatic and Boussinesq approximations, and has a free sea surface. The numerical code is based on the Bryan-Cox model, except that the rigid-lid assumption is relaxed to accommodate a free surface. Details of model formulation are given in Chao et al. (1996). The model is driven by tides. The initially quiescent but stratified ocean is forced by sea level oscillations imposed on open boundaries. A single diurnal tidal component is used to illustrate the essential results. Model dependence on tidal frequencies will be commented on later in Section 5. Winds and thermohaline forcing at the sea surface are excluded.

The initial vertical stratification is given by the typically observed temperature profile in Nan Wan (Fig. 5). The observed salinity varies little with depths; salinity in the model is therefore fixed at the commonly observed value of $34.6 \mathrm{psu}$. The initially motionless ocean is driven by sea level oscillations imposed on open boundaries to the east, west and south of model interior. On the eastern boundary, sea level $(\eta)$ varies 


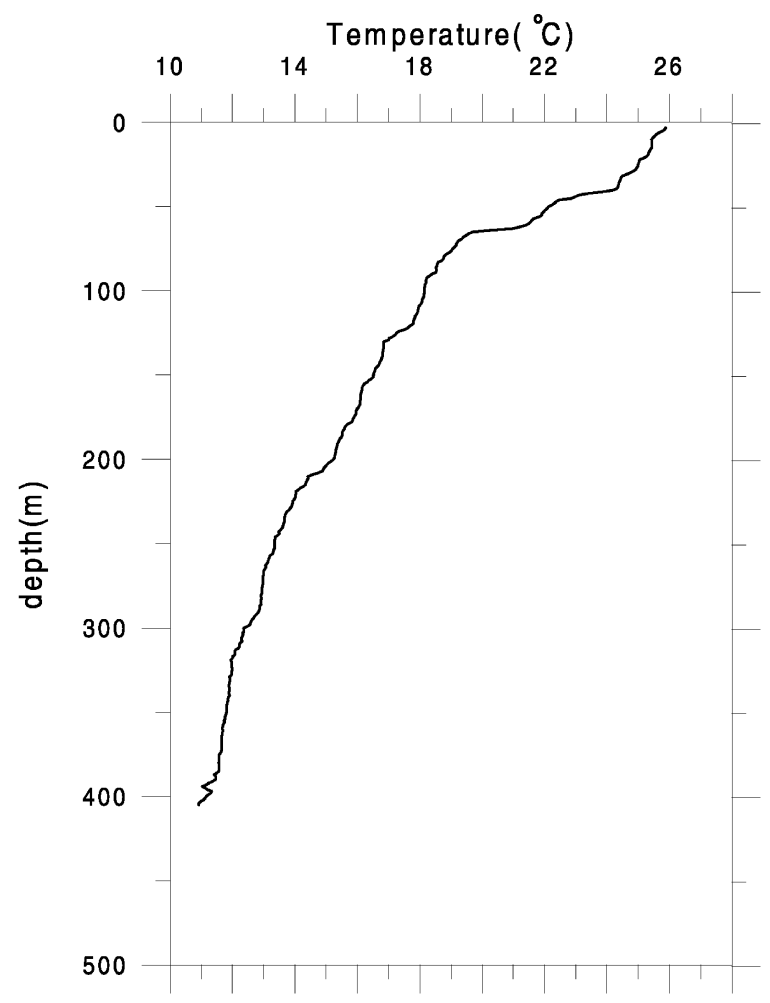

Fig. 5. A typical temperature profile measured by R/V Ocean Researcher I at 120.45E, 21.50N on 27 March 1991. The strong thermocline exists between 50 and $90 \mathrm{~m}$ below sea surface.

with time $(t)$ according to

$$
\eta=A \cos \left(\frac{2 \pi t}{T}\right)
$$

where $A$ is the amplitude and $T=24 \mathrm{~h}$. Unless otherwise stated, $A$ is fixed at $80 \mathrm{~cm}$. Seal level on the western boundary differs from (1) by a time lag $(\phi)$, so that

$$
\eta=A \cos \left(\frac{2 \pi(t-\phi)}{T}\right)
$$

where $\phi$ is normally fixed at $0.25 \mathrm{~h}$. Sea level along the southern boundary varies linearly from Eq. (1) on the east to Eq. (2) on the west. The strength of tidal currents essentially increases with $\phi$, which has been tuned to produce the observed tidal strength. In waters of $30 \mathrm{~m}$ depth, the time lag of $0.25 \mathrm{~h}$ is approximately the time required for a barotropic Kelvin wave to travel from OLB to MBT.

Leaving the sea level aside, other boundary conditions are as follows. Let $(u, v, w)$ be positive eastward, northward and upward, respectively. Horizontal velocity 
components on open boundaries are extrapolated from the model interior, so that

$$
\partial(u, v) / \partial n=0,
$$

where $n$ is normal to a boundary. The vertical velocity is zero on open boundaries. Temperatures $\left(T_{w}\right)$ on open boundaries are advected by flow normal to the boundary, so that

$$
\partial T_{w} / \partial t+u_{n} \partial T_{w} / \partial n=0
$$

In case of inflow, inflow temperature is given the characteristic temperature profile as shown in Fig. 5. All solid boundaries are impenetrable, impermeable and no-slip. At the sea surface, no momentum or heat flux is imposed. At the ocean bottom, there is no normal flow or heat flux, and a quadratic bottom stress is imposed with a dimensionless drag coefficient of 0.0025 . Using sea level fluctuations to derive the interior flow, the set of open boundary conditions is identical to that typically used in the estuarine modeling community. Readers are referred to, for example, Chao et al. (1996) for the efficacy of these boundary conditions.

Horizontal mixing is Laplacean; the mixing coefficient is $80000 \mathrm{~cm}^{2} / \mathrm{s}$ for momentum and $8000 \mathrm{~cm}^{2} / \mathrm{s}$ for temperature. Vertical viscosity and diffusivity depend on the Richardson number according to the formulae given by Pacanowski and Philander (1981). The model resolution is $200 \mathrm{~m}$ in horizontal directions and $7.5 \mathrm{~m}$ in the vertical. There are 121 grids zonally and 81 grids meridionally, producing a domain of $24 \mathrm{~km}$ in east-west directions and $16 \mathrm{~km}$ in north-south directions. In the numerical experiments to be illustrated below, land masses to the east and west of the Bay are stretched out zonally to intersect the open boundaries at the right angle. This measure is strictly out of stability concerns. If computationally stable, solutions are visually indistinguishable whether the land masses are stretched zonally or not near eastern and western boundaries. Occasional instability results if land masses are not stretched out to open boundaries. The model resolves barotropic and baroclinic components with different time steps using the standard mode-splitting technique (Simons, 1974). The time step is $0.3 \mathrm{~s}$ for the barotropic mode and $12 \mathrm{~s}$ for the baroclinic mode. The Coriolis parameter is fixed at $5.448 \times 10^{-5} \mathrm{~s}^{-1}$. Starting from a motionless state, both

Table 1

List of experiments

\begin{tabular}{ll}
\hline Experiment & Topography \\
\hline A1 & Realistic basin \\
A2 & A1 plus extended MBT \\
B1 & Rectangular bay, flat bottom \\
B2 & Trapezoidal bay, flat bottom \\
B3 & B2 plus eastern ridge \\
B4 & B3 plus seamount \\
\hline
\end{tabular}

See Fig. 6 and associated discussion for B-series of experiments 
flow and density fields reached a cyclical equilibrium after about 3 tidal cycles. The fourth tidal cycle is used to facilitate the analysis.

Bottom topography and coastline geometry are quite complex in and around Nan Wan. A lengthy process of elimination is needed to remove topographic and coastline features systematically. Table 1 lists crucial experiments in the elimination process. Starting from the all-inclusive realistic basin, experiment A1 provides a reference solution describing the evolution of recirculation eddies in relation to prevailing tidal currents. In experiment A2, MBT cape is extended southward to the same latitude as the southern tip of OLB. The purpose is to check whether the unequal length of two capes favors the development of cyclonic recirculation eddy during ebbs. The simplification did not significantly reduce the profound flood-ebb disparity of recirculation eddies. More drastic simplifications of bottom topography and coastline geometry are called for.

Approaching from the other extreme, the B-series of experiments starts simple and builds to the complex. Fig. 6 illustrates the type of basins employed in this series. In

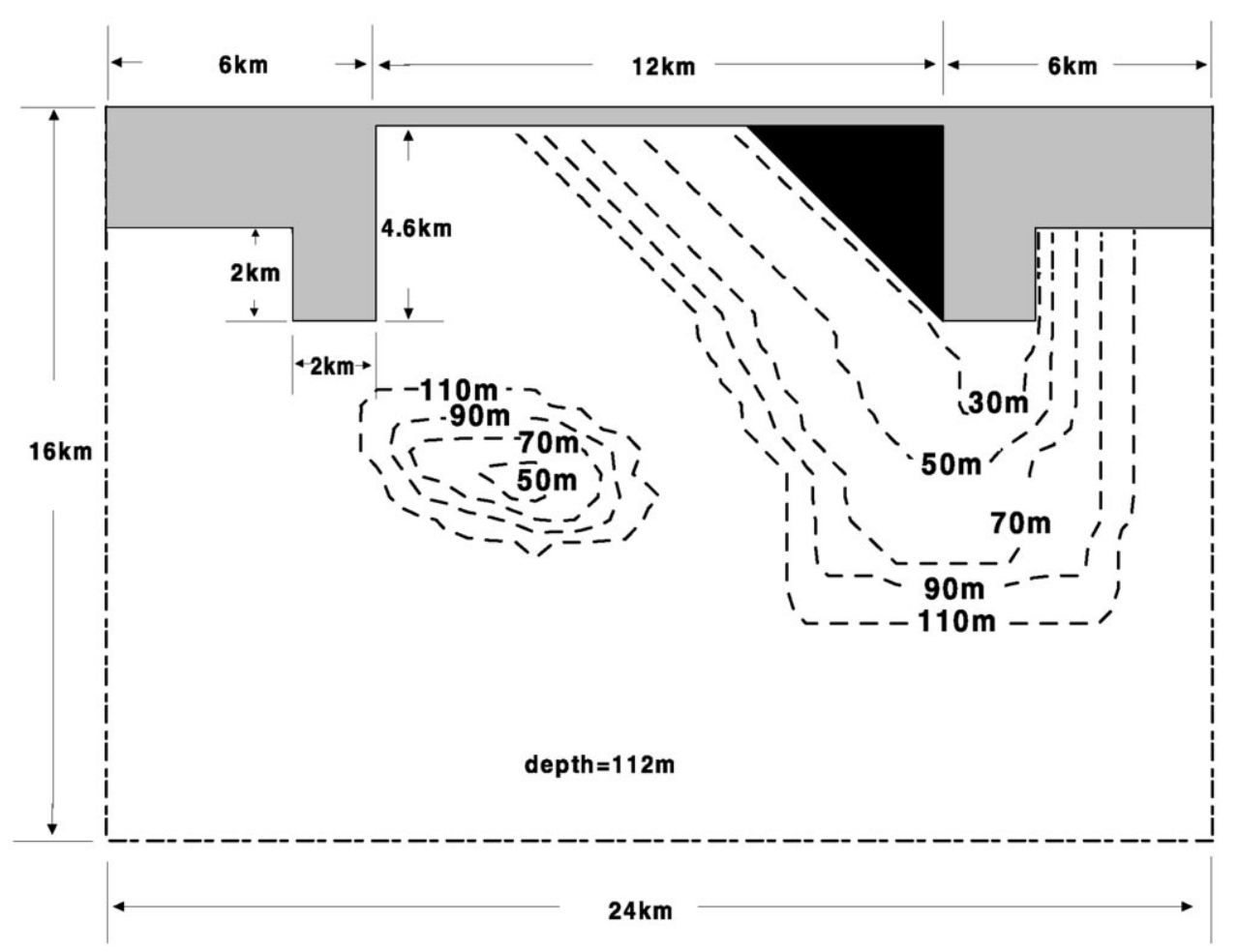

Fig. 6. A suite of idealized basins employed in B-series of experiments. Dashed contours are isobaths (in m) of a ridge and a seamount rising above the otherwise flat sea floor. Hatched triangle represents additional land mass. Experiment B1 employs the flat-bottomed basin with rectangular embayment. Experiment B2 includes the triangular land mass. The ridge around the eastern cape is further included in B3. The seamount elliptical in shape is further included in B4. 
experiment B1, the basin geometry is simplified to the extreme; the ocean bottom is flat and the semi-enclosed basin is rectangular. In this case the cyclonic eddy during ebb and anticyclonic eddy during flood are comparable in size and strength. Experiment B2 is similar to B1, except that the eastern boundary of the bay is slanted, running in southeast-northwest directions. The added triangular land area is hatched in Fig. 6. Experiment B3 differs from B2 in that a bottom ridge is added around the eastern cape. The ridge extends southward of the eastern cape and also forms a continental shelf on eastern half of the bay; isobaths are shown in Fig. 6. Experiment B4 further improves B3 by adding a zonally elongated seamount, of which isobaths are shown in Fig. 6. This is the experiment that contains the essential topographic features leading to the favorable development of cyclonic eddy during ebbs.

\section{Numerical results with realistic or semi-realistic basin}

\subsection{Realistic topography}

When realistic topography as shown in Fig. 1 is employed in experiment A1, the anticyclonic recirculation eddy during flood and cyclonic recirculation eddy during ebb differ markedly. Fig. 7 shows selected snapshots of surface flow fields and
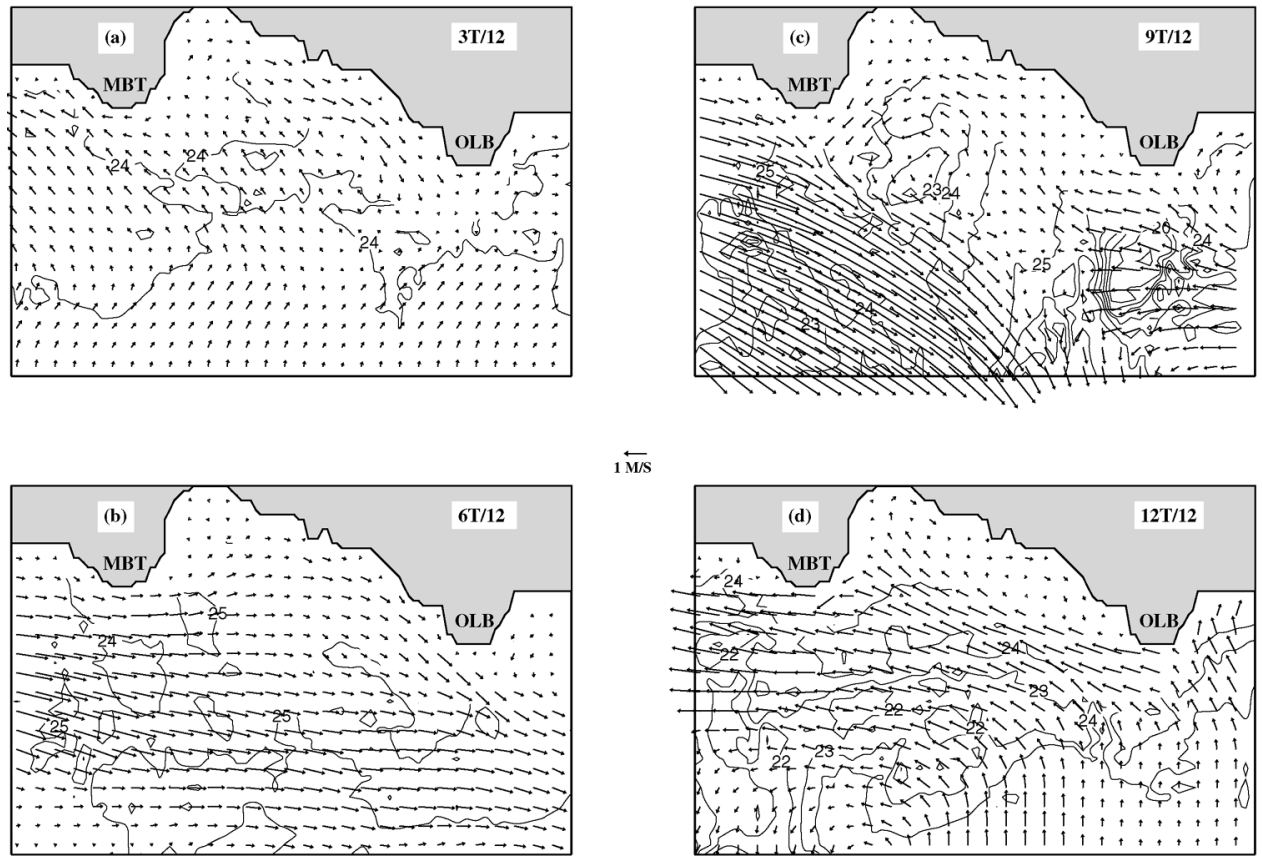

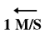

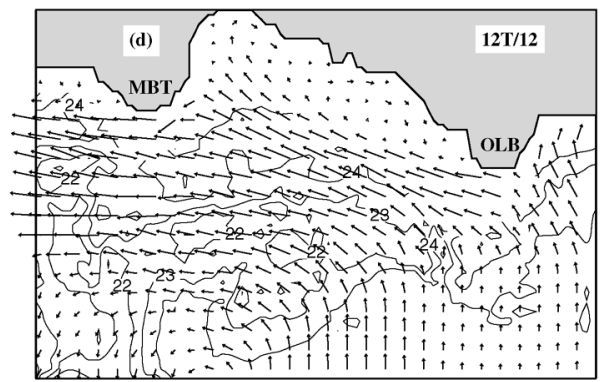

Fig. 7. Surface currents and temperature fields (in ${ }^{\circ} \mathrm{C}$ ) of the sixth layer for (a) $t=3 T / 12$, (b) $t=6 T / 12$, (c) $t=9 T / 12$ and (d) $t=T$ during the fourth tidal cycle from experiment A1. 
temperature contours for the sixth layer (at $41.25 \mathrm{~m}$ below the mean sea surface) during the fourth tidal cycle. Of interest here are different pathways taken by flood and ebb tidal streams. Flood current follows the arc-shaped deep channel westward and therefore intensifies to the north of the zonally elongated seamount (Fig. 7d). Ebb or eastward current intensifies mainly to the south of the seamount (Fig. 7b), especially at the end of ebb (Fig. 7c). These patterns of prevailing tidal currents would suggest a cyclonic residual circulation around the seamount when averaged over a tidal cycle. The anticyclonic eddy, if any, is localized over the continental shelf on the eastern side of the Bay as the flood (westward) current diminishes, gaining maximum strength at the sixth hour (top left panel). When present, the anticyclone remains localized during the flood and does not expand westward to the deeper portion of the embayment. On the contrary, the cyclonic recirculation eddy (top right panel) is far more expansive. The cyclone begins to appear in the western half of the Bay near the end of ebb current, expanding southward and eastward while losing strength well into the beginning of the flood current.

The localized anticyclone at the end of flood current does not induce sizable temperature variations. Instead, temperatures inside the bay are nearly uniform from the 0th hour to the 6th hour during the spin-up of anticyclone. Since the anticyclone is confined to the shallow continental shelf, large temperature variations due to vertical movement of isotherms are unlikely. In contrast, the expansive cyclone over the deep portion of the Bay is able to induce upwelling of cold waters from below. At the 18th hour, temperatures within the eddy are about 2.5 degrees colder than surrounding waters. Also at the 18th hour, a cold anomaly begins to appear south of OLB, apparently caused by the ridge-induced upwelling as the flood current begins to emerge on the eastern side of the basin.

For recirculation eddies, sizable deviations from cyclostrophy or geostrophy are illustrated by sea surface topographies at 6 th, 12 th, 18 th and 24 th hour (Fig. 8). The cyclonic eddy is fully developed when sea level is the lowest inside the Bay. The anticyclonic eddy is better developed when the high tide is receding. Centers of both eddies are not associated with localized sea level anomalies as one would expect from geostrophy or cyclostrophy. It is also apparent that the evolving cyclonic eddy is more cyclostrophic than geostrophic. Taking the cyclone at the 18th hour as an example, the eddy radius $(r)$ is about $4 \mathrm{~km}$ and the swirling speed $(v)$ is about $50 \mathrm{~cm} / \mathrm{s}$. The centrifugal acceleration $\left(v^{2} / r\right)$ is about $6.25 \times 10^{-3} \mathrm{~cm} / \mathrm{s}^{2}$, which is far greater than the Coriolis acceleration $(f v)$ of $2.5 \times 10^{-3} \mathrm{~cm} / \mathrm{s}^{2}$ given an appropriate $f$. Two hours earlier, the cyclonic eddy is about equal in strength but half as large. The initial cyclone is even more cyclostrophic. To further quantify the deviation from geostrophy in the rapidly evolving four-dimensional field requires extensive illustrations, and is beyond the objective of this study.

Fig. 9 shows the residual circulation pattern after averaging over a tidal cycle. The major cyclonic gyre is around the zonally elongated seamount. Speeds of the residual cyclonic circulation range up to one-third of maximum tidal currents. The strong residual flow is made possible because prevailing flood and ebb currents do not follow the same path (Fig. 7). For tidal currents over a small-amplitude sand ridge, it is known that the so-called "Coriolis torque" produces anticyclonic vorticity over the 

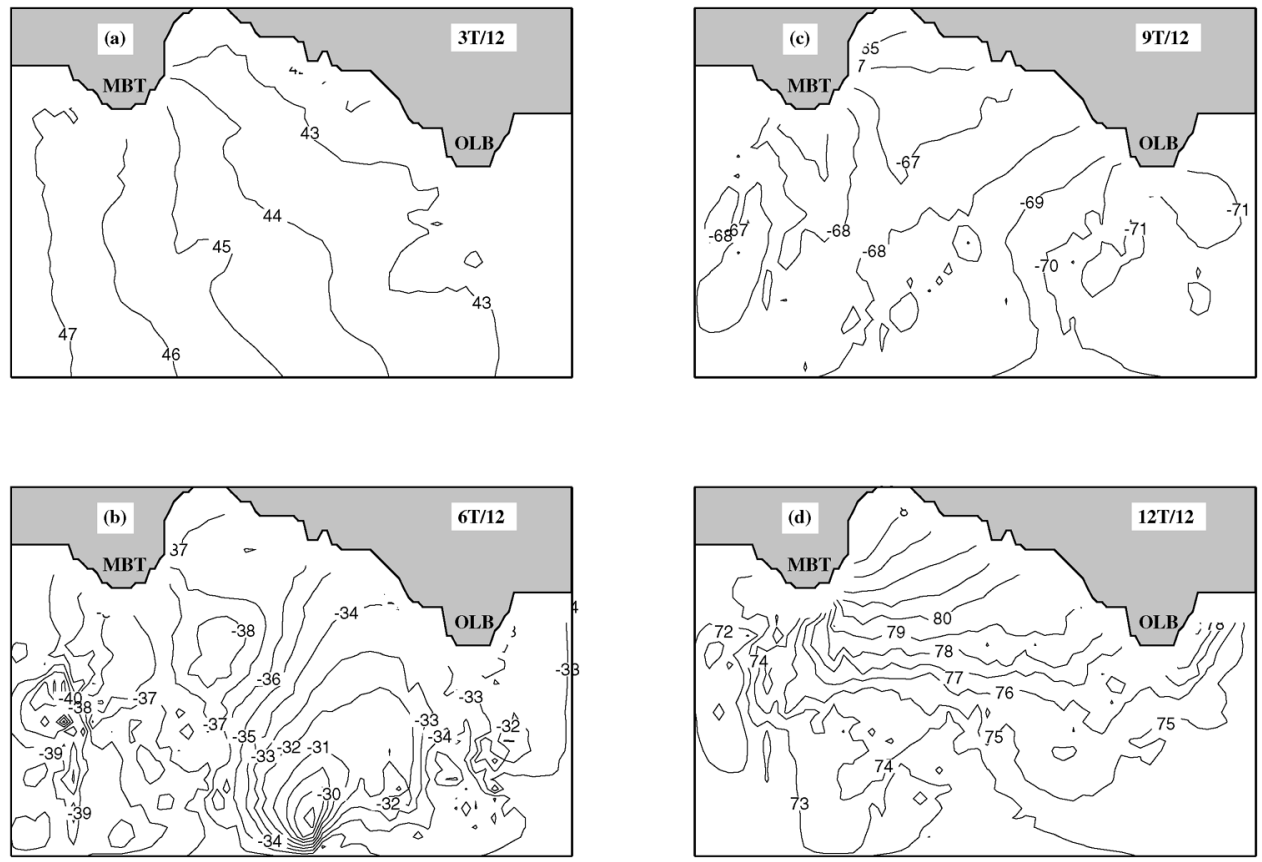

Fig. 8. Sea level fields (in $\mathrm{cm}$ ) corresponding to Fig. 7 from experiment A1.

ridge (Zimmerman, 1981). In the present setting the zonally elongated seamount is large in size and amplitude, deflecting both flood and ebb currents anticyclonically. Thus, flood (westward) and ebb (eastward) currents tend to be displaced to the north and south of the seamount, respectively, producing the cyclonic residual eddy. Following this scenario, the anticyclonic deflection and the resulting cyclonic residual eddy should reduce in strength and size with decreasing height of the seamount. This has been verified by additional experiments not reported herein.

There is also an anticyclonic residual eddy to the west of OLB in Fig. 9. This is the remnant of transient lee eddy induced during the flood (Fig. 7d). Dynamically, the eddy is akin to headland-induced eddies reported by Pingree and Maddock (1977) and Geyer and Signell (1991). More on this will be given later.

\subsection{Extended $M B T$}

By extending the length of west cape (MBT) to the same latitude as the east cape (OLB), experiment A2 did not produce new features (figures not shown). The extended MBT hardly affects the development of anticyclone on the eastern side of the Bay during the flood period. The cyclone grows slightly larger as a result of extended MBT. Apparently, unequal excursion of two capes is not responsible for the flood-ebb disparity of recirculation eddies. 


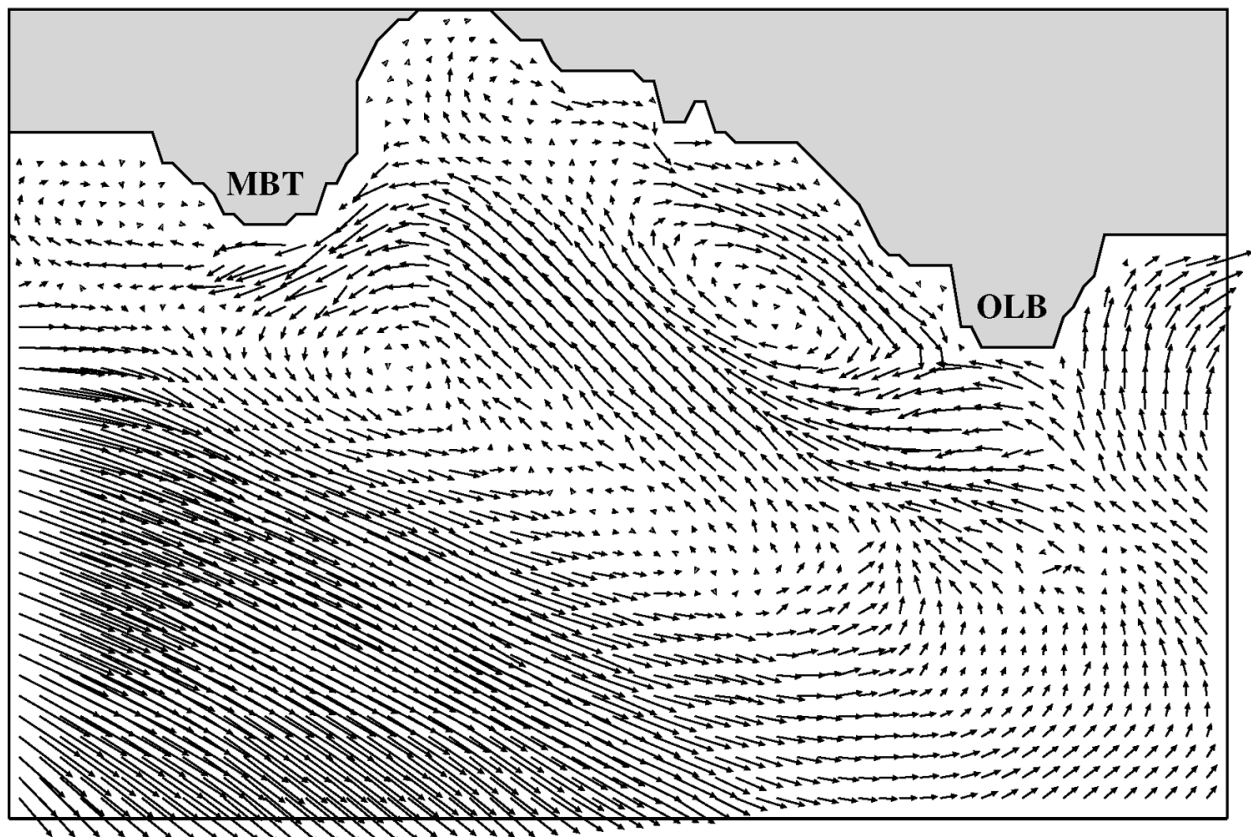

Fig. 9. Residual circulation from experiment A1, after averaging over a tidal cycle.

\section{Numerical results with idealized basins}

The process of elimination in the preceding section did not identify mechanisms leading to the flood-ebb disparity of recirculation eddies. Further elimination along that line was becoming increasingly difficult. To simplify the topography further inevitably introduces new topographic features affecting the flow field in the basin. It pays to approach from the other extreme. Starting from the most idealized basin, complicating topographic features are added successively. Results from this alternative approach follow.

\subsection{Flat-bottomed basins}

Experiment B1 employs a flat and rectangular basin as shown in Fig. 6. Fig. 10 shows the fully developed anticyclone and cyclone during the fourth tidal cycle. The sizes of the anticyclone and cyclone are comparable; the latter is slightly larger than the former. Recirculation eddies are preferably located on the leeward side of a cape; this is related to the large dimension of the embayment. In smaller embayments, recirculation eddies, whether cyclonic or anticyclonic, are centered about the axis of the bay (Lin et al., 1994). Meridional tidal currents apparently modulate the north-south span of cyclone and anticyclone. The flood current 
$1 \mathrm{M} / \mathrm{S}$
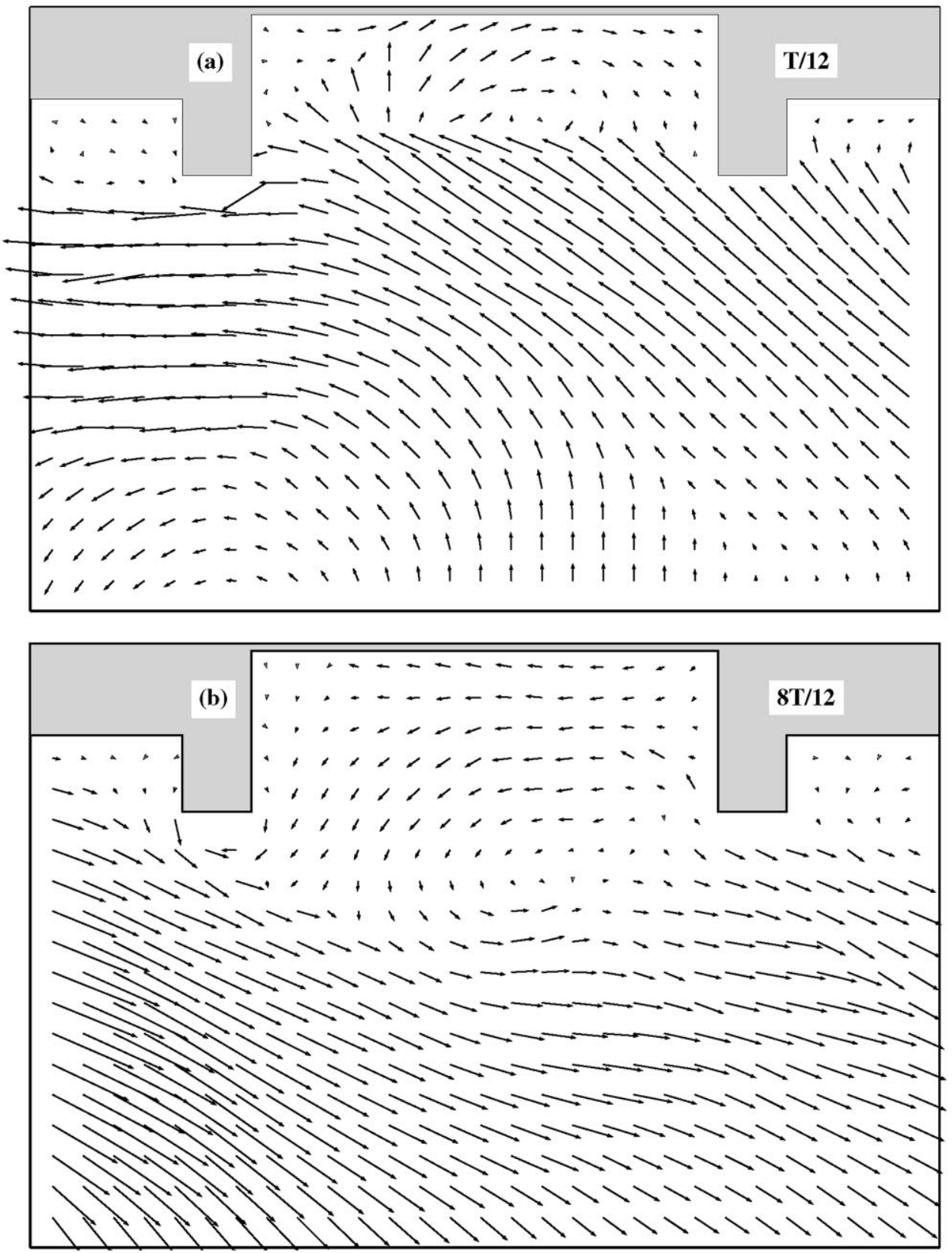

Fig. 10. Surface currents at (a) $t=T / 12$ and (b) $t=8 T / 12$ from experiment B1 during the fourth tidal cycle. 
compresses the anticyclone bayward, while the ebb current draws the cyclone out of the bay.

By adding a slanted boundary on the eastern side, experiment B2 essentially provides a geometrical distortion to the flow field inside the embayment. Results are otherwise unremarkable and therefore not shown. As in Fig. 10, the cyclonic eddy is somewhat larger than the anticyclonic eddy: both occupy good portions of the bay. Itcan be concluded that the slanted coastline is not responsible for the flood-ebb disparity of recirculation eddies in the bay.

\subsection{Ridge around the eastern cape}

Sizable disparity between anticyclonic and cyclonic eddies begins to emerge if a ridge around the eastern cape is included. In experiment B3, the western flank of the ridge extends into the embayment, forming a continental shelf along the slanted eastern boundary. Fig. 11 shows surface circulation fields at times the cyclone and anticyclone care better developed. The potential vorticity constraint requires the flow to gain anticyclonic turning tendency as tidal currents flow over the ridge. In consequence, the flood current at $t=T / 12$ shows more northward or bayward tendency leeward (westward) of the ridge, and the recirculating anticyclone is compressed to the eastern side of the bay. While the compression of anticyclone is desirable, the recirculating cyclone during ebb current becomes much weaker and is drawn out of the bay. It can be concluded that the bottom ridge around the eastern cape is chiefly responsible for the suppression of anticyclonic recirculation eddy.

The recirculating anitcyclone during flood is akin to the lee eddy near a headland in Vineyard Sound, MA (Geyer and Signell, 1991). In their observations and numerical simulations, flood current gains maximum anticyclonic vorticity as it flows over shallow waters adjacent to the headland. The lee anticyclone subsequently expands downstream from maximum flood to the end of flood. The topography around MBT is similar and induces a like response. Anticyclonic vorticity is initially generated over the ridge south of OLB neat the maximum flood, and is subsequently drawn into the eastern side of the bay by advection. Since responses are similar, illustrations of vorticity are omitted.

\subsection{Zonally elongated seamount}

Further inclusion of the zonally elongated ridge in experiment B4 brings the model results much closer to reality (Fig. 12). The channel between the zonally elongated seamount and land mass to the north provides a conduit for the flood current. Channeled into the bay, the flood current suppresses the anticyclonic recirculation eddy further to the east. Passing over the zonal seamount, the ebb current gains anticyclonic rotation tendency and is therefore deflected further offshore. The cyclonic recirculation eddy is better developed and occupies the entire bay. Thus, the zonally elongated seamount not only produces an expansive recirculating cyclone during the ebb current, but also suppresses anticyclonic recirculation eddy to the east 


\section{$1 \mathrm{M} / \mathrm{S}$}
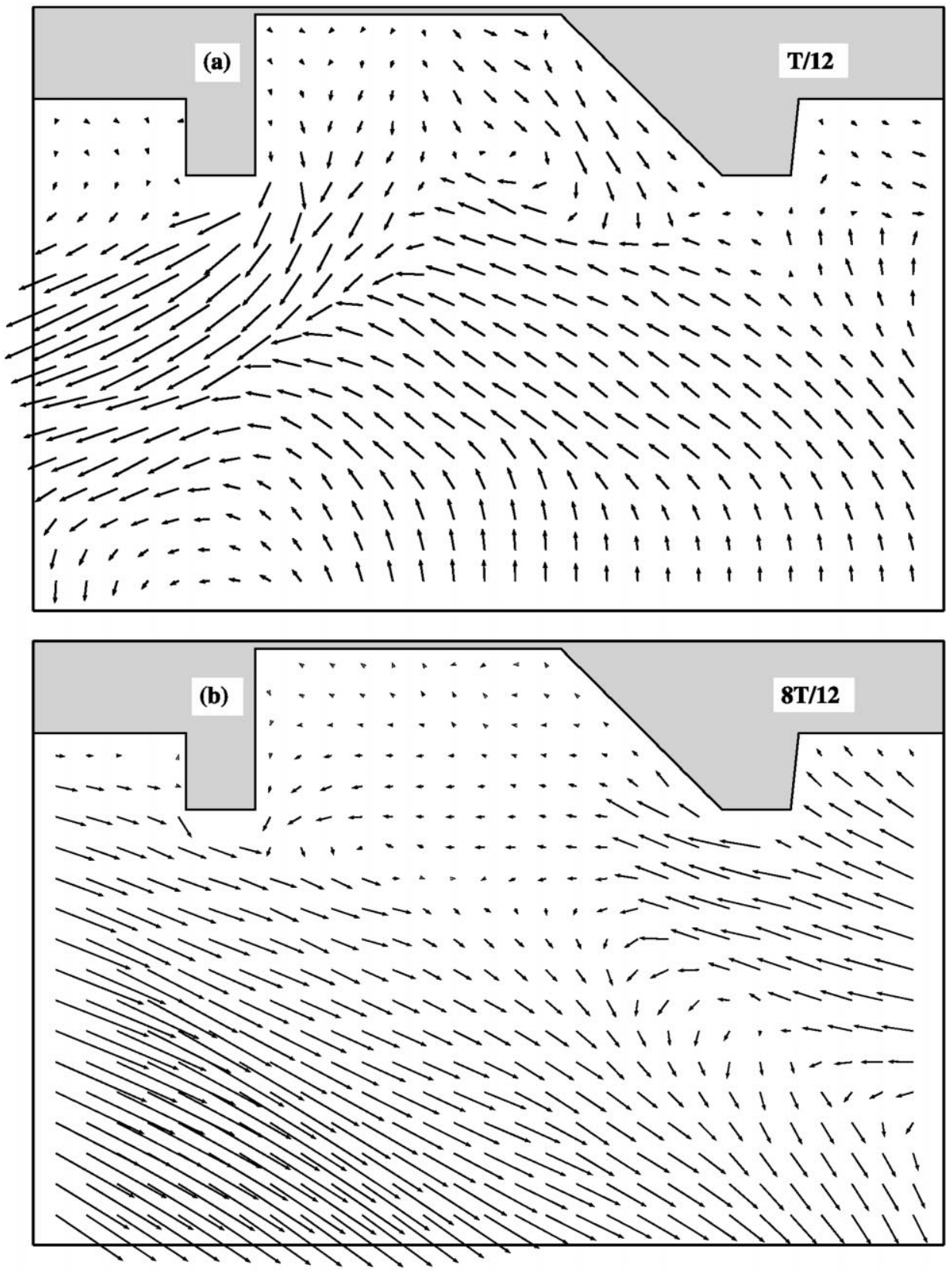

Fig. 11. Same as in Fig. 10 except from experiment B3. 


\section{$1 \mathrm{M} / \mathrm{S}$}
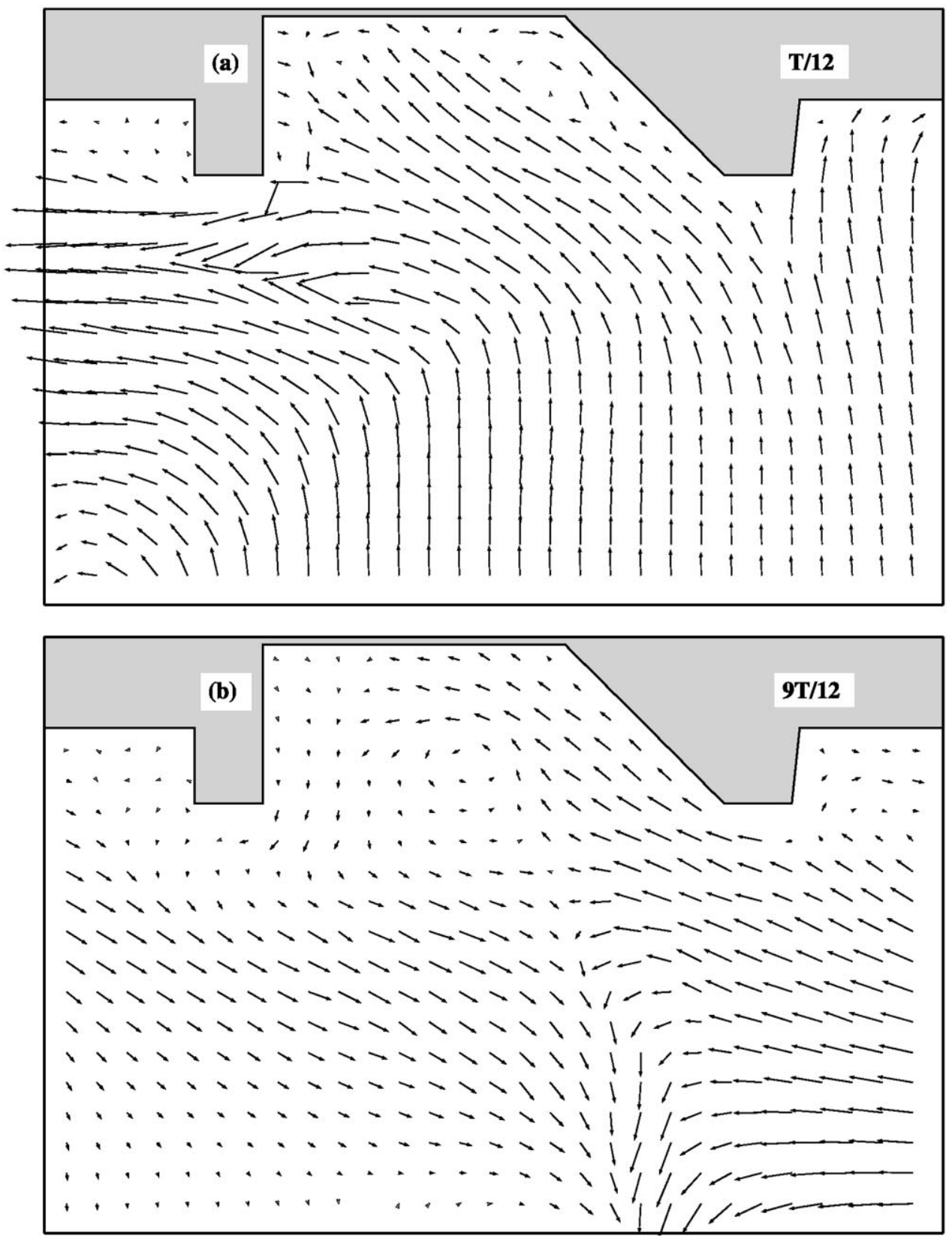

Fig. 12. Same as in Fig. 10 except from experiment B4 and the cyclone is displayed at $t=9 T / 12$. 
during the flood current. Adding more topographic features can further enhance the model realism. Nevertheless, our objective is met because Fig. 12 contains essential features revealed by observations and model simulations using the realistic basin geometry.

\section{Discussion and conclusions}

For tidal currents oscillating in directions tangential to the open boundary of an embayment, recirculation eddies usually develop during both flood and ebb periods. These transient eddies are generally much stronger than the tidally induced residual flow, which consists of a pair of counter-rotating eddies on either side of a headland (Pingree and Maddock, 1977; Zimmerman, 1980). There are many ways to interpret the existence of transient recirculation eddies. For embayments much narrower than a tidal excursion length $\left(L_{\mathrm{t}}\right)$, recirculation eddies can be regarded as being driven by the shear of tidal currents offshore (Lin et al., 1994). For bays wider than $L_{t}$, recirculation eddies with dimensions comparable to $L_{\mathrm{t}}$ should develop leeward of the front cape (Geyer and Signell, 1991). In Nan Wan the tidal excursion length is about $8 \mathrm{~km}$, smaller than the width of the Bay. Thus the eddy size is limited by $L_{\mathrm{t}}$ rather than by the dimension of the basin. The earth's rotational effect also sets in for large embayments; eddies tend to expand or shift in the direction of Kelvin wave propagation.

Recirculation eddies owe their existence to the inability of prevailing tidal currents to flow directly into the basin. A recirculation eddy will likely be enhanced or diminished if the prevailing tidal current outside the embayment is somehow deflected seaward or bayward. Bottom topographic features outside an embayment provide an effective means to deflect tidal currents. Thus, in addition to the bay width and the earth's rotation, bottom topographies outside the bay also affect the flood-ebb disparity between recirculation eddies.

In a rotating fluid, flow over a seamount gains negative vorticity to conserve potential vorticity. For a slow incoming flow, the negative vorticity stays over the seamount. For a swift incoming flow, the negative vorticity is advected downstream (Vaziri and Boyer, 1971; Chao and Janowitz, 1979), deflecting the current anticyclonically in the lee. Potential vorticity conservation is a steady-state constraint that can be extended to diurnal and semi-diurnal frequencies; this is clear from the numerical simulation of Geyer and Signell (1991). Thus, the bottom ridge around OLB deflects the flood current bayward and in the process reduces the size of the recirculating anticyclonic eddy. The zonally elongated seamount, on the other hand, deflects the ebb current seaward and consequently enhances the cyclonic recirculation eddy in the Bay. In addition, the channel between the landmass and the zonal seamount guides the flood current into the Bay and therefore reduces the size of anticyclone further. The profound disparity between recirculation eddies during flood and ebb periods is essentially caused by the two topographic features.

Parallel numerical experiments other than the ones shown herein are too numerous to be reported below. Major conclusions from these side experiments help enhance our intuition. The strength of recirculation eddies is roughly proportional to the 
strength of prevailing tidal currents offshore. This is conceivable even if one follows a linear way of thinking. Further, since it takes time to spin up recirculation eddies, their strength also depends on tidal frequency. The same experiment, if conducted using a semidiurnal tide, would greatly reduce the strength or even occurrence of recirculation eddies. It is therefore not surprising that the observed eddies occur daily rather than semi-daily, and preferably during spring periods.

To generalize our findings to elsewhere, a semi-enclosed basin with a prominent sill blocking the middle reaches of the mouth region is found to be most conducive to the flood-ebb disparity of recirculation eddies. A cyclone is preferred to an anticyclone under this setting. Of secondary importance is the bottom ridge stretching out from the capes; the consequent anticyclonic deflection of tidal currents in and out of the embayment modulates the eddy strength and size in ways as depicted in Geyer and Signell (1991). A modest length difference between the two capes is not effective in modulating recirculation eddies. The model realism can be enhanced in several ways. Foremost of all, realistic tidal constituents should be imposed on open boundaries; this requires deployment of deep water tide gages along open boundaries of the model domain. Meteorological forcing should also be included to infer seasonal variations of the recirculation eddies.

While realistic tidal model of Nan Wan still awaits development, this work serves as the first step by pointing out dominant mechanisms producing the disparity between anticyclonic and cyclonic recirculation eddies. Observationally, continuous monitoring of the Bay using H.F. radar (Prandle and Player, 1993) would be highly desirable. Unfortunately, the technology is still under development in Taiwan. Nan Wan Bay is not biologically productive because the intense upwelling occurs only three or four times in a spring-neap cycle, lasting a few hours each. The CZCS type imagery would generally fail to capture the action unless the temporal resolution can be drastically improved.

\section{Acknowledgements}

Professor N.K. Liang of Institute of Oceanography, National Taiwan University, generously shared his observational results with us, and made this theoretical investigation possible. Authors HJL and KLF were supported by the National Research Council of the Republic of China under grant NSC 86-2611-M-002A-010. Author SYC was supported by the U.S. National Science Foundation under grant OCE9504959.

\section{References}

Chao, S.-Y., Janowitz, G.S., 1979. The effect of a localized topographic irregularity on the flow of a boundary current along the continental margin. Journal of Physical Oceanography 9, 900-910.

Chao, S.-Y., Shaw, P.-T., Wu, S., 1996. Deep water ventilation in the South China Sea. Deep-Sea Research Part I 43 (4), 445-466. 
Chao, S.-Y., Boicourt, W.C., Wang, H.V.C., 1996. Three-layered circulation in reverse estuaries. Continental Shelf Research 16, 1379-1397.

Chen, C.T.A., Ou, S.-C., Chung, Y.-C., Wu, C.-K., Chun, L.-R., 1994. Research of living resources around the nuclear power plant in southern Taiwan. Tech. Rep. 20, College of Marine Sciences, National Sun Yat-Sen University, pp. 195.

Geyer, W.R., Signell, R., 1991. Measurement and modeling of the spatial structure of nonlinear tidal flow around a headland. In: B.B. Parker (Ed.), Tidal Hydrodynamics. Wiley, New York, pp. 403-418.

Lee, H.-J, Chao, S.-Y., Fan, K.-L., Wang, Y.-H., Liang, N.K., 1997. Tidally induced upwelling in a semienclosed basin: Nan Wan bay. Journal of Oceanography 53, 467-480.

Li, H.-W., 1987. A numerical predicative model of tides in the seas adjacent to Taiwan. Proceedings of National Science Council, Part A: Physical Science and Engineering 11 (1), 74-89.

Liang, N.K., Lein, S.L., Chen, W.C., Chang, H.T., 1978. Oceanographic investigation in the vicinity of Ma-An-San and Nan Wan bay. Special publication No. 18, National Taiwan University, pp. 207.

Lin, C.-T., Fan, K.-L., Chao, S.-Y., 1994. Small-scale plumes from a semi-enclosed basin: Yin-Yang bay. Terrestial, Atmospheric and Oceanic Sciences 5, 91-107.

Pacanowski, R.C., Philander, S.G.H., 1981. Parametrization of vertical mixing in numerical models of tropical oceans. Journal of Physical Oceanography 11, 1443-1451.

Pingree, R.D., Maddock, L., 1977. Tidal eddies and coastal discharge. Journal of Marine Biology Association UK 57, 869-875.

Prandle, D., Player, R., 1993. Residual currents through the Dover Strait measured by H.F. Radar. Estuarine, Coastal and Shelf Science 37, 635-653.

Simons, T.J., 1974. Verification of numerical models of Lake Ontario, Part I: Circulation in spring and early summer. Journal of Physical Oceanography 4, 507-523.

Su, J.-C., Hung, T.-C., Chiang, Y.-M., Tan, T.-H., Chang, K.-H., Shao, K.-T., Hwang, P.-P., Lee, K.-T., Huang, C.-C., Huang, C.-Y., Fan, K.-L., Yeh, S.-Y., 1980. An ecological survey on the waters adjacent to the nuclear power plant in southern Taiwan. Special publication No. 7, National Scientific Committee on Problems of the Environment Academia Sinica, Taipei, Taiwan, ROC, pp. 115.

Vaziri, A., Boyer, D.L., 1971. Rotating flow over shallow topographies. Journal of Fluid Mechanics Part I $50,79-95$.

Wang, J., Chern, C.-S., 1995. Preliminary Observation of Internal Surges in Tung-Kang, ACTA Oceanographica Taiwanica 35, 17-40.

Zimmerman, J.T.F., 1981. Dynamics, diffusion and geomorphological significance of tidal residual eddies, Nature 290, 549-555. 